\title{
AFECÇõES NEUROLóGICAS DA INFÂNCIA: FATORES TÓXICOS AGINDO NO PERIODO PRÉ-NATAL
}

\author{
Olavo NeRY *
}

O fato de terem sido apresentadas, durante os ültimos 20 anos, provas impressionantes da possivel repercussão de influências exógenas sôbre o desenvolvimento embrionário humano demonstra a importância prática da investigação o-togênica e torna muito atuais os problemas da patologia pré-natal. Embora não exista ainda acôrdo completo sôbre o conteúdo e o conceito de uma patologia de periodo pré-natal, duas tendências se definem nitidamente: a genética humana com sentido primordialmente etiológico, a anatomia patológica se orientando para os fatos patogênicos.

Os tecidos e órgãos, uma vez lesados com certa intensidade, "nunca mais esquecem a injúria sofrida" (Goertler, 1958), restando sempre uma deficiência permanente, funcional ou morfológica. A nosologia do periodo pré-natal, isto é, os distúrbios da gematogênese, assim como a avaliação dos fatôres etiológicos, constitui o campo da disontologia ou disontogênese e as lesões residuais dai resultantes integram grupo das disembriopatias.

O organismo humano responde a uma mesma noxa com uma cronoespecificidade diferente, também chamada disposição patocrônica, o que é, em outros têrmos, a designação de períodos criticos de desenvolvimento (Courville ${ }^{1}$ ) ou momentos patogênicos ( $\mathrm{Maffei}^{4}$ ). Segundo Goertler ${ }^{2}$ podemos ordenar os períodos de desenvolvimento em progênese, germogênese, blastogênese, embriogênese, período fetal, desenvolvimento placentário, a que corresponderiam os respectivos distúrbios patológicos - patologia da pré-fecundação, germopatias, blastopatias, embriopatias, fetopatias, placentopatias.

A patologia da progênese, tarefa primordial do geneticista, encontrou recente campo de investigações no efeito das radiações sôbre os cromossomas. O estudo da gametogênese, incluindo os transtornos das vias genitais masculina e feminina, condicionadas por anomalias no terreno, vem se acrescentar de um campo muito importante de investigação: o uso de anti-conceptivos.

A patologia da germogênese, compreendendo os transtornos do concepto em seu desenvolvimento, encarada em sua dupla vertente de diferenciação morfológica ou funcional, encontra ampla literatura desde as obras de Ballantyne (1902) até os aspectos modernos tratados, entre tantos outros, por

Relatório apresentado ao IV Congresso Brasileiro de Neurologia (Porto Alegre, 5 a 9 de julho de 1970).

- Professor de Neurologia Pediátrica na Escola Médica de Pós-Graduação da Pontificia Universidade Católica (Guanabara). 
Warkany (1947), Potter (1952), Regel (1957), Goertler (1960) e Toendury (1962). O vertiginoso desenvolvimento do embrião, sempre precedido por um aumento do metabolismo e a interferência neste, assim como o deslocamento dos gradientes metabólicos em um sentido cranial a caudal, da parte dorsal para a ventral, da esquerda para a direita (Bellamy, 1919; Child, 1924; Hymn, 1927), modifica o risco das partes e dos órgãos, justificando falar-se de "periodos sensiveis de desenvolvimento germinal".

Em vista das numerosas lacunas na investigação das atividades metabólicas do embrião humano, tem-se recorrido aos estudos comparativos em outros organismos (metazoários, vertebrados e mamiferos), como os de Needham (1931), Ishikawa (1955), Hsia (1959). O estudo do "metabolismo alterativo" inclui o transtôrno do labil equilíbrio somato-anímico, que conduz a uma disregulação funcional, logo seguida por uma lesão orgânica, processo que pode ser superado por fatôres compensadores ou contra-reguladores (Goertler).

Quanto ao cérebro, o período que oferece maior vulnerabilidade às diversas noxas se situa entre a segunda e a décima segunda semanas; para os globos oculares e o coração, entre a terceira e a oitava; para as extremidades, entre a terceira e a nona. Através de experimentos animais foi possivel determinar com relativa precisão o período crítico para as distintas deformidades, embora reconhecendo a variável atividade dos diferentes agentes patógenos. Foi observado que, no início dos processos teratogênicos, ocorrem, com freqüência, extensas necroses, além do retardo do curso ontogênico normal. Os aspectos tissulares atípicos, as hemorragias, o edema, a inflamação fetal, como reação complexa do aparelho conetivo vascular, sòmente tardiamente encontrada, são outros aspectos patológicos. Falam alguns autores de uma minusvalência pré-natal, residuo de uma lesão embrionária que curou sem defeito visivel e que seria paralela ao conceito de abiotrofia de Gowers. As anomalias placentárias são consideradas como acometimento simultâneo do embrioblasto e do trofoblasto. A patologia da placenta recebeu grande impulso com os estudos de Hermannn (1949, 1952, 1958), Kaese (1949), Bayer (1953), Krone (1958, 1960), Mey (1961) e Becker (1962).

Os processos patológicos ocorridos no período fetal, embora menos evidentes, assumem importância singular, incluindo a mucoviscidose, peritonite mecônica asséptica, fetose diabética, eritroblastose fetal, infecções virais pré-natais tardias (varicela, variola). Entre os fatôres internos que desempenham papel etiológico nos transtornos da ontogenia foram estudadas a disposição e a constituição, incluindo a resistência e a hipersensibilidade (Ishikawa, 1955).

O estudo dos fatôres externos capazes de determinar transtornos disontogênicos experimentais, assim como o dos defeitos do desenvolvimento embriológico humano assume importância cada vez maior. $O$ gérmen humano mostra-se muito sensivel a várias causas físicas, quimicas, alimentares e infecciosas que atuem efetivamente sôbre êle. A noxa atuante pode determinar transtornos dismorfogênicos ou não deformantes do desenvolvimento embrionário. 
Entre as causas físicas avulta a radiação gama. A influência dos raios cósmicos constitui capítulo da maior relevância. Macht e Lawrence (1955) estudando estatisticamente a progênie de radiologistas norte-americanos e, Tanaka e Okura (1958) a de técnicos de radiologia, encontraram números significativamente maiores de defeitos congênitos, inclusive do sistema nervaso, de alterações na proporção entre os sexos (cromossoma $X$ ), neoplasias, esterilidade conjugal. Turpin e Lejeune (1957), analisando a descendência de 4428 pessoas irradiadas com mais de $300 \mathrm{r}$, encontraram alteração na proporção relativa entre os sexos.

Quase tôdas as substâncias estudadas em Toxicologia têm possibilidades teratógenas. Já há muito tempo estavam incluidas substâncias farmacológicas como o quinino, mais recentemente a aminopterina (Hisrsch, 1960; Warkan, Baudry, Hornstein, 1959), sendo a ação desta substância comparada à dos raios Roentgen. E comprovada a ação teratógena dos solventes (substâncias lipo-solúveis, derivados fenólicos, corantes azóicos). Acentua-se a intensidade das alterações quando são empregadas substâncias de ação citostática (venenos mitóticos), conforme comunicações de Toendury (1955), Murphy, Dagg e Karnofsky (1957), Goertler (1958), Giroud, Tuchman e Duplessis (1962). Substâncias com atividade antibiótica e hormonal possuem igualmente um componente citostático, como as sulfamidas (Landauer, 1949), estilbenos (Toendury, 1956), a actinomicina-D (Tuchman, Duplessis e Mercier-Parot, 1960). São teratógenos em potencial os anti-diabéticos de configuração molecular sulfamídica (Campbell, 1961).

O XXII Congresso da Federação de Sociedades de Ginecologia e Obstetricia de Língua Francesa (Paris, 1968) estudou o problema dos efeitos iatrogênicos, para o concepto, de medicamentos administrados às gestantes. Segundo as suas conclusões a administração de androgênios e de alguns progestogênios no início da gestação pode provocar alterações na genitalia do concepto. Perigosos são a testosterona e seus sais, a etiterona, os derivados dos noresteróides.

Os anovulatórios, tomados inadvertidamente durante as primeiras semanas de gravidez, podem produzir malformaçōes; da mesma forma podem ser teratogênicosos preparados hormoniais usados como testes de gravidez, sobretudo os gestagênios derivados dos 17-noresteróides (Hartl, 1961; Overzier, 1961; Zimmer, 1961). É duvidosa a produção de alterações permanentes após a corticoterapia, embora teòricamente possuam os corticosteróides ação teratogênica (distúrbios na arquitetura do maciço facial e, por conseguinte, a possibilidade de comprometimento do sistema nervoso, visto como o mesoderma pré-cordal influencia o telencéfalo e o diencéfalo). Neste sentido, assume significação a advertência de Lecomme para os acidentes tardios devidos ao acometimento do feto pela hormonoterapia de ação prolongada durante a gravidez. Da mesma forma tem sido chamada atenção para as substâncias de ação catabolizante (Doerr, Becker e Goertler, Neuweiler e Richter, 1961).

Embora não sendo reconhecido como determinante de anomalias congênitas, o $\mathrm{I}^{131}$ e os iodetos que atravessam com facilidade a barreira placentária, 
podem fixar-se sôbre a tiróide do feto que è extremamente sensivel a partir do quarto mês. Os anti-tireoideanos sintéticos podem determinar, no feto, conseqüências secundárias ao hipotireoidismo materno. Vem aumentando a evidência de que, em muitos casos de cretinismo, a lesão cerebral ocorreu in utero pela falta de quantidades adequadas de hormônio tireoidiano materno ou não passagem do mesmo pela placenta para o feto.

Depois que Wiedemann (1961) chamou a atenção sôbre o aumento ostensivo de amelias e focomelias na Alemanha Ocidental, o que foi confirmado por outros investigadores (Hepp, 1962; Smithels, 1962) foi aceita a existência de embriopatia talidomídica (Lenz e Knapp, 1962; Welkere, Hungerland, 1962; Weicker, Cachmann, Pfeiffer, Gleis, 1962). A essa condição, caracterizada pela ausência de membros ou parte dêles, associada freqüentemente à nevos flamígeros, microftalmo, anomalias do pavilhão auditivo, defeitos cardiovasculares e atresias do aparelho digestivo e urogenital, ocasionando uma mortalidade de cêrca de $30 \%$, Wiedmann designou "síndrome dismélica". Alguns autores são mais moderados no seu julgamento, embora também considerem a ação teratógena dessa substância contida em numerosos preparados hipnóticos e tranquilizantes (Petersen, 1962; Pliess, 1962; Wiedmann, 1962). Os efeitos teratógenos se dariam com a ingestão da talidomida pela gestante entre a quinta e a sexta semana de gravidez.

O "problema da talidomida" ocupa hoje o ponto central da investigação teratológica em todo o mundo. O seu mecanismo patogênico ainda não está seguramente estabelecido, sendo feitas várias conjecturas: distúrbios no metabolismo dos gens? bloqueio enzimático? inibição do ácido ribonuclêico na célula ou durante a divisão celular? Teria ainda a talidomida uma ação imuno-supressiva que impediria o abortamento dos ovos malformados?

A maioria dos medicamentos psicotrópicos tem fraca toxicidade mas, dada a afinidade celular específica cada vez maior dêsses produtos químicos, impõese extrema prudência na sua administração, sobretudo nas 13 primeiras semanas de gravidez. Alguns dos derivados fenotiazínicos (promazina, clorpromazina, triflupromazina, acepromazina, levo-promazina e prometazina) provocaram malformações em animais em experiência. Foi publicado um caso de focomelia consecutivo à administração de prometazina (Fenergan). O amplictil e seus derivados não apresentaram perigo. Entre os derivados da rauwolfia, a reserpina não ocasiona danos ao concepto nem à gestante, devendo entretanto ser mencionada a ação cumulativa no feto.

Entre os tranquilizantes, os meprobamatos são nefastos (Werboff). Dos anti-depressivos, a imipramina (Tofranil) determina lesões nos animais. Há raras observações de vícios congênitos em filhos de gestantes que receberam medicamentos nas primeiras semanas de gravidez, não sendo possível, entretanto, afirmar-se a sua ação teratogênica.

Entre os psico-estimulantes, a fenometrazina (Preludin), usada atualmente como anoréxico, foi incriminada na etiologia de malformações.

Os inquéritos realizados por Serment e Ruf, Caderas de Kerleau e Durand, Gellé e Délecour constituíram a parte clínica de um simpósio a cujo 
subsídio recorremos. O estudo experimental coube a Tuchmann e Duplessis. Foram discutidos os fundamentos da teratogênese, a ação dos diversos medicamentos durante a gestação, os mecanismos envolvidos na sua atuação, quando teratogênica, e a significação dos dados experimentais; foi salientado, entretanto, que a extrapolação para o gênero humano é difícil, mesmo porque muitos fármacos nocivos a outras espécies não o são obrigatòriamente à mulher gestante ou ao concepto.

Serment e Ruf estudaram ainda os anti-histamínicos. A meclizina, acusada como responsável por grande número de malformações, foi proibida em alguns países a pedido dos organismos sanitários suecos em seguida à tragédia da talidomida. Foram atribuídas à meclizina as seguintes malformações: spina bífida, meningocele, anencefalia, sindatilia, amelia, estenose pilórica, imperfuração anal, hérnias diafragmáticas, sendo o seu uso desaconcelhado às gestantes. A ciclizina tem nítida ação teratogênica experimental, sendo a sua prescrição desaconselhada à gestante em face do grande número de malformações fetais registradas após seu uso.

Dos anti-convulsivantes, os barbitúricos não parecem nocivos ao feto no consenso unânime dos neurologistas e como comprovam as doses maciças absorvidas por mulheres grávidas que tentaram o suicídio. A carbazepina (Tegretol) deve ser evitada nos três primeiros meses.

O ácido acetilsalicílico, a amidopirina e os salicilatos não têm ação nociva sôbre o embrião ou o feto. Não foram observados acidentes embrionários ou fetais com o uso de cardiotônicos (digitalina ou ouabaina).

Dos anti-coagulantes, a heparina não atravessa a placenta, mas os antivitamínicos $\mathrm{K}$ (dicumarínicos, derivados da Indana) atravessam a placenta e foram responsabilizados por casos de descolamento prematuro da placenta e hemorragias do feto in utero.

\section{$R$ E F E R N C I A S}

1. Courville, C. B. - Pathology of the Nervous System. Pacific Press Publ. Assoc., 1945.

2. GOERTTLER, K. - Germopatia em Genetica Humana. Versão castelhana. Editorial Toray, Barcelona, 1966.

3. KOLLROS, J. J. - Endocrine Influence in Neural Development. Symposium on Growth of the Nervous System. J. \& A. Churchill, Londres, 1968.

4. MAFFEI, W. E. - Bases Anátomo-Patológicas de Neuriatria e Psiquiatria. São Paulo.

5. PEIPER, A. - Cerebral Function in Infancy and Childhoond. New York, 1963.

6. PRATT, R. T. C. - The Genetics of Neurological Disorders. Oxford University Press, Londres, 1967.

7. REBOllo, M. A. - Neurologia Pediatrica. Delta Editorial, Montevideo, 1970.

8. THALHAMMER, O. - Patologia Pre-Natal. Salvat Editores, Barcelona, 1970.

9. THORN, I. - Cerebral Symptoms in the Newborn. E. Muskgaard, Copenhague, 1969.

R. Gustavo Sampaio 374, ap. 801 - Leme ZC-07 - Rio de Janeiro, GB - Brasil. 